NASA Technical Memorandum 102329

$$
\begin{aligned}
& 1 N-24 \\
& 235034 \\
& -08
\end{aligned}
$$

\title{
Mechanics of Damping for Fiber Composite Laminates Including Hygro-Thermal Effects
}

(NASA-TM-102329) MECHANICS OF DAMPING FUR FIBER COMPOSITE LAMINATES INCLUOING HYGRO-THERMAL EFFECTS (NASA. LEWIS
Research (enter) $28 \mathrm{p}$
CSCL 110

$63 / 24 \quad \begin{array}{ll}\text { Unclas } \\ 0235034\end{array}$

N90-10185

D.A. Saravanos and C.C. Chamis

Lewis Research Center

Cleveland, Ohio

Prepared for the

30th Structures, Structural Dynamics, and Materials Conference cosponsored by the AIAA, ASME, ASCE, AHS, and ASC

Mobile, Alabama, April 3-5, 1989 


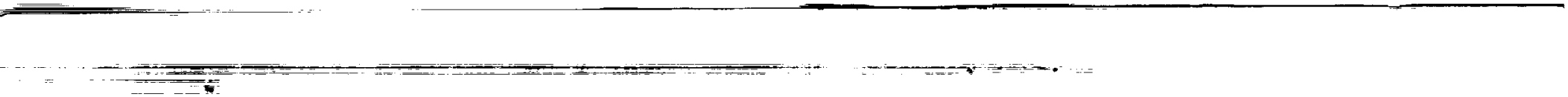
$-5$

$\therefore=$

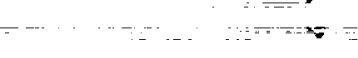

$+\cdots-$

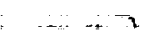

$=\ldots+\cdots+\cdots$

$=$ 


\section{TABLE OF CONTENTS}

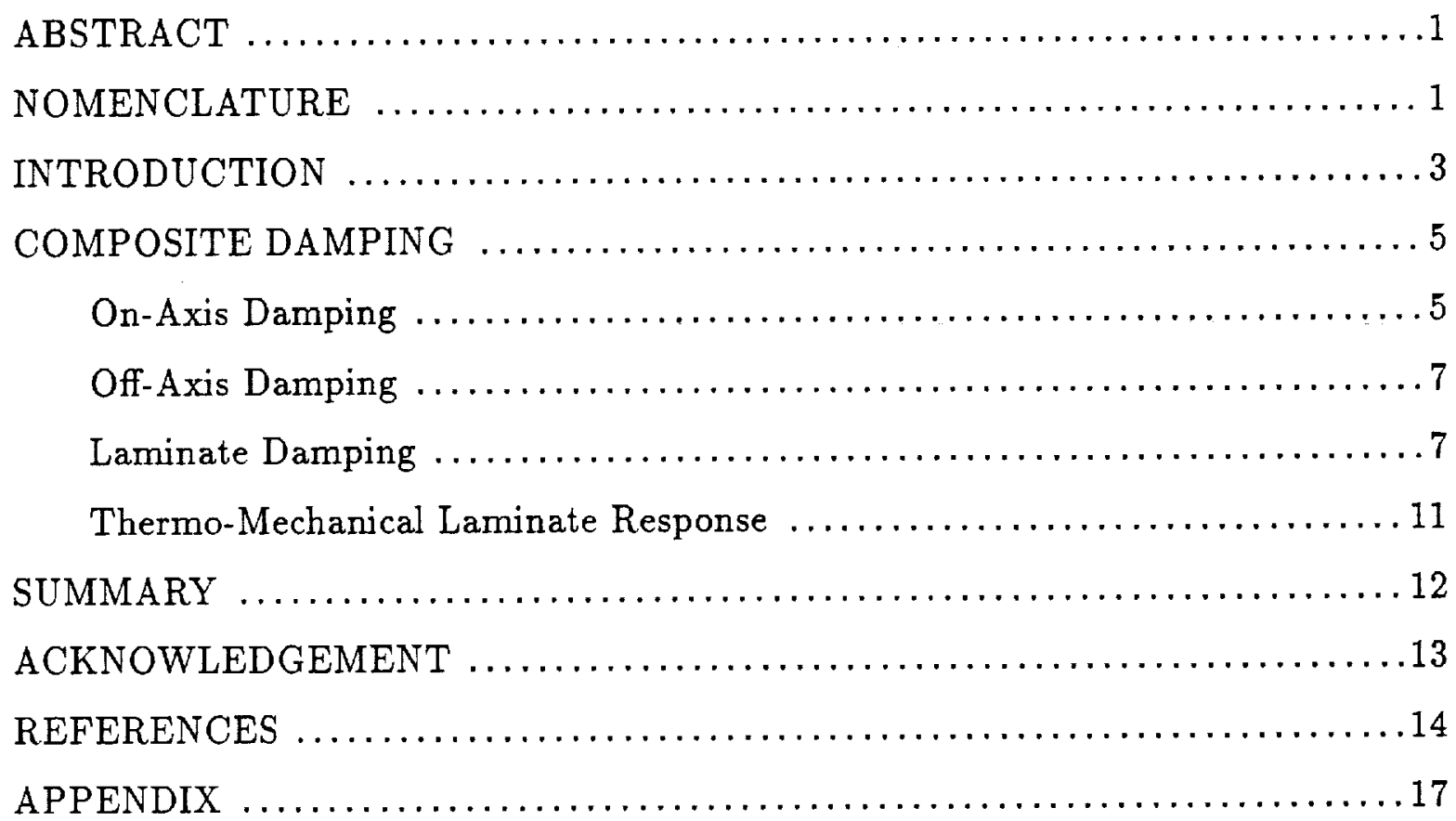




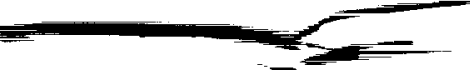




\title{
MECHANICS OF DAMPING \\ FOR FIBER COMPOSITE LAMINATES \\ INCLUDING HYGRO-THERMAL EFFECTS
}

\author{
D.A. Saravanos* and C.C. Chamis** \\ National Aeronautics and Space Administration \\ Lewis Research Center \\ Cleveland, Ohio 44135
}

\begin{abstract}
An integrated mechanics theory has been developed for the modeling of composite damping from the micromechanics to the laminate level. Simplified, design oriented equations based on hysteretic damping are presented for on-axis plies, off-axis plies, and laminates including the effect of temperature, moisture, and interply hysteretic damping. The temperature rise within vibrating composite laminates resulting from strain energy dissipation is also modeled, and their coupled hygro-thermo-mechanical response is predicted. The method correlates well with reported damping measurements. Application examples illustrate the effect of various ply, laminate, and hygro-thermal parameters on the overall damping performance of composite laminates.
\end{abstract}

\section{Nomenclature}

$\left[A_{D}\right]: \quad 3 \times 3$ Extensional damping matrix.

$[A]: \quad 3 \times 3$ Extensional stiffness matrix.

$\left[C_{D}\right]: \quad 3 \times 3$ Coupling damping matrix.

$[C]: \quad 3 \times 3$ Coupling stiffness matrix.

$\left[D_{D}\right]: \quad 3 \times 3$ Flexural damping matrix.

$[D]: \quad 3 \times 3$ Flexural stiffness matrix.

${ }^{*}$ National Research Council-NASA Research Associate.

**Senior Research Scientist. 
$d_{f}: \quad$ Fiber diameter.

$E: \quad$ Normal modulus.

$\left[E_{l}\right],\left[E_{c}\right]: \quad$ On-axis and off-axis ply stiffness matrices.

$G: \quad$ Shear modulus.

$H: \quad$ Interply distortion energy coefficient.

$k: \quad$ Volume ratio.

$N_{l}: \quad \quad$ Number of plies.

$M: \quad$ Percentage of moisture by weight.

$P: \quad$ Property.

$T: \quad$ Temperature.

$t: \quad$ Ply thickness.

$W, \delta W: \quad$ Stored and dissipated strain energies.

$z$ : $\quad$ Distance from laminate mid-surface.

$\delta L: \quad$ Thickness of interply layer.

$\epsilon: \quad$ Engineering strain.

$\epsilon^{\circ}: \quad$ Mid-plane engineering strain vector.

$\kappa: \quad$ Curvature vector.

$\nu: \quad$ Poisson's ratio.

$\sigma: \quad$ Stress.

$\psi$ : $\quad$ Specific damping capacity.

\section{Subscripts}

$\begin{array}{ll}b: & \text { Ply bottom. } \\ c: & \text { Ply (off-axis). } \\ D: & \text { Damping. } \\ f: & \text { Fiber. } \\ g d: & \text { Glass transition, dry. } \\ g w: & \text { Glass transition, wet. } \\ l: & \text { Ply (on-axis). } \\ L: & \text { Laminate. } \\ m: & \text { Matrix. }\end{array}$



$M: \quad$ Mechanical.
o: $\quad$ Reference.
rp : $\quad$ Ply interface.
$t: \quad$ Ply top.

\section{Direction}

$\begin{array}{ll}11: & \text { Normal longitudinal. } \\ 22: & \text { Normal in-plane transverse. } \\ 33: & \text { Normal out-of-plane transverse. } \\ 12: & \text { Shear in-plane. } \\ 23: & \text { Shear out-of-plane. } \\ 13: & \text { Shear out-of-plane. } \\ s: & \text { In-plane normal, off-axis, x-direction. } \\ n: & \text { In-plane normal, off-axis, y-direction. } \\ x x: & \text { In-plane shear, off-axis. }\end{array}$

\section{Introduction}

With the continuing evolution of composite materials and the simultaneous requirements for higher performance and lower operational costs, more and more composites are targeted toward structural applications involving combined dynamic mechanical, thermal and hygral loading. Composite materials are principally preferred in such applications because of their advanced elastic properties and tailoring capability to individual design requirements. They also have the potential for incorporating significant and tailorable passive damping into the candidate structure. Polymer matrix composites are sensitive to temperature and moisture variations, and as a result of low thermal conductivities and high damping, they usually exhibit temperature increases in case of steady-state cyclic response ${ }^{1}$. Consequently, coupling exists between the mechanical, thermal and hygral dynamic response of composite structures, in that thermal and hygral (moisture) loads affect the structural vibrational characteristics, while the vibrational response can induce 
thermal loads into the structure and alter the moisture content. In order to attain ultimate utilization of composite materials, in terms of elastic and damping properties, unified composite mechanics are needed for characterizing the damped vibrational, thermal, and hygral coupled response of composite materials and structures.

Previous work on the subject is mainly focused on the elastic properties of composite materials and the undamped response of composite structures. Although knowledge of the elastic properties and their hygro-thermal behavior ${ }^{2}$ is a fundamental step for predicting the dynamic response of a structural system, it seems that incorporation of material damping capabilities into the analysis, together with the hygro-thermal effect, is a step that still needs to be accomplished. Hashin ${ }^{3}$, Adams and co-workers ${ }^{4-5}$, and Chang and Bert ${ }^{6}$ have provided micromechanics theories for predicting the damping in continuous fiber composite plies, however, they have mostly assumed nondissipative fibers, have restricted the analysis to normal longitudinal and in-plane shear damping capacities, and have overlooked the anisotropic fiber damping properties. Analogous theoretical and experimental work for the damping in discontinuous fiber composites is presented in references ${ }^{7-10}$. In addition to ply micromechanics, the damping of off-axis plies and laminates of symmetric ply configurations has been also investigated by Schultz and Tsai ${ }^{11-12}$, Bacon and Adams ${ }^{13-14}$, Bert ${ }^{15}$, and Gibson and co-workers ${ }^{7,9}$.

A new micromechanics theory for the in-plane and out-of-plane normal damping, as well as, in-plane and out-of-plane shear damping of composite plies has recently been developed by Saravanos and Chamis ${ }^{16}$. The methodology assumes anisotropic dissipative fiber properties, includes the friction due to broken fibers, and incorporates hygro-thermal effects on the elastic and damping properties of the material. In the current paper, the previous work is extended to composite angle plies and laminates. In this manner, an integrated methodology is now available for predicting all mechanical properties of composite laminates, including damping, necessary for characterizing the vibrational response of composite structures. The present mechanics theory for laminate damping is complete, in that it covers general laminate configurations, in contrast to other reported theories which are mostly applicable to symmetric laminates. The mechanics incorporates the effect of temperature and moisture on the ply and laminate damping properties, and includes 
contributions due to hysteretic damping at the interply interface. Further, the method accounts for the mechanical, hygral, and thermal coupling effects in composite laminates and their respective interactions.

\section{Composite Damping}

This section briefly reviews the synthesis of on-axis ply specific damping capacities (SDC's) from the constituent properties of fiber and matrix. The transformation law for off-axis SDC's and the formulation of the laminate damping capacity are then presented. The effect of temperature, moisture, and interply layer damping on the laminate damping is also included into the method. Applications of the method are also illustrated, and whenever possible, the results are compared to reported experimental measurements.

\section{On-Axis Damping}

Hysteretic Damping. Starting from the fundamental constitutive elements of a composite ply, simplified micromechanics equations for the 6 SDC's of a unidirectional composite along the material axes have been synthesized. The on-axis ply SDC's are described by equations (A1-A11) in Appendix and in ref. 16. The equations are based on the assumption that the dissipated strain energy of the composite is equal to the sum of strain energies individually dissipated within the matrix and the fibers. They also assume linearly viscoelastic matrix and fibers, isotropic elastic and dissipative properties for the matrix, and anisotropic (but transversely isotropic) elastic and dissipative properties for the fibers. The assumed stress and strain distributions within the fiber and matrix are similar to those developed, utilized, and verified in previous micromechanics theories by Chamis

and co-workers 17,18. As seen in equations (A1-A11), the dissipative ply properties are principally related to the individual damping and elastic properties of the ply constituents and the fiber volume ratio (FVR).

Figure 1 illustrates the relation of damping coefficients to the FVR for a HM-S high modulus surface treated graphite fiber, polyester matrix composite system. The polyester matrix was simulated with the IMLS matrix of ICAN ${ }^{2}$. The damping properties of matrix and fibers were taken from ref. 4. As seen in Figure 1, the results correlate well with experimental measurements reported in the same reference. The longitudinal SDC is a fiber controlled property, as it quickly approaches the value of the fiber SDC and then remains mostly insensitive to the fiber volume ratio. The transverse normal and all shear 
SDC's are predominantly matrix controlled and their values are gradually reduced as the FVR is increased.

Hygro-Thermal Effect. Variations in the temperature and moisture content of a polymer matrix composite will primarily affect the properties of the plastic matrix. Previous studies ${ }^{19}$ have shown that the hygro-thermal effect on most mechanical properties of the matrix can be expressed as,

$$
\frac{P_{M}}{P_{o}}=\left[\frac{T_{g w}-T}{T_{g d}-T_{o}}\right]^{0.5}
$$

The inverse form of eq. (1) is proposed for the hygro-thermal effect on the matrix damping, based on the fact that the damping of polymers increases with the temperature,

$$
\frac{P_{D}}{P_{o}}=\left[\frac{T_{g d}-T_{o}}{T_{g w}-T}\right]^{q}
$$

The wet glass transition temperature is:

$$
T_{g w}=T_{g d}\left(0.005 M_{l}^{2}-0.1 M_{l}+1\right)
$$

The exponent $q$ can be easily correlated to experimental data of each individual polymer matrix. In the rest of the paper, the value $q=0.5$ is assumed. The hygro-thermal effect is incorporated into the ply properties via the micromechanics equations. Figure 2 presents the effect of temperature and moisture on the in-plane shear SDC, for a HM-S graphite fiber/IMHS (intermediate modulus high strength) epoxy composite ply. The reference temperature is $70^{\circ} \mathrm{F}\left(21^{\circ} \mathrm{C}\right)$, and the glass transition temperature for the matrix is $420^{\circ} \mathrm{F}\left(215.5^{\circ} \mathrm{C}\right)$. As seen in Figure 2, the effect of temperature on the shear damping may be quite significant, as well as, the combined effect of elevated temperature and moisture. Analogous results were obtained for the transverse and out-of-plane shear SDC's. In contrast, the hygro-thermal effect on the longitudinal normal SDC was rather negligible. The hygro-thermal parameters are expected to dominate the transverse and shear damping properties of a composite ply, as they are predominantly controlled by the matrix. 


\section{Off-Axis Damping}

The off-axis composite damping (ie. the damping associated with off-axis stresses of an angle ply) is related to the on-axis damping of a ply by the following transformation law which is based on the invariance of the dissipated strain energy ${ }^{16}$ :

$$
\left[\psi_{c}\right]=\left[R_{\sigma}\right]^{T}\left[\psi_{l}\right]\left[R_{\sigma}^{-1}\right]^{T}
$$

In the previous expression the on-axis damping matrix is diagonal:

$$
\left[\psi_{l}\right]=\left[\begin{array}{ccc}
\psi_{l 11} & 0 & 0 \\
0 & \psi_{l 22} & 0 \\
0 & 0 & \psi_{l 12}
\end{array}\right]
$$

while the off-axis damping matrix is in general fully populated:

$$
\left[\psi_{c}\right]=\left[\begin{array}{lll}
\psi_{c x x} & \psi_{c x y} & \psi_{c x s} \\
\psi_{c y x} & \psi_{c y y} & \psi_{c y s} \\
\psi_{c s x} & \psi_{c s y} & \psi_{c s s}
\end{array}\right]
$$

The fully populated damping matrix illustrates the coupling due to the material anisotropy. The equivalent axial SDC's of the ply, ie. the net SDC's observed when individual cyclic stresses are applied to the ply, are synthesized from the previous damping matrix ${ }^{16}$. As shown in ref. 16, the analytical predictions correlate well with experimental data. Typical variations of the diagonal off-axis SDC's with respect to the ply angle for a $50 \%$ FVR HMS/IMHS composite ply are shown in Figure 3. The $\mathrm{x}$-axis SDC $\psi_{c x x}$ is increasing rapidly as the ply angle is increasing, peaks near 60 degrees, then gradually drops to the value of transverse SDC at 90 degrees. The $y$-axis SDC $\psi_{c y y}$ follows exactly the opposite trend as was expected. The shear SDC $\psi_{c s s}$ is maximum at 0 and 90 degrees and minimum at 45 degrees.

\section{Laminate Damping}

The laminate SDC is based on the damping contributions of each individual ply and the interply layers in between. It seems that interply effects have been included into the damping mechanics of laminates for the first time. The laminate SDC is expressed in the form of extensional, coupling, and flexural $3 \times 3$ damping matrices.

$$
\left[A_{D}\right]=\sum_{i=1}^{N_{l}}\left(z_{t}-z_{b}\right)_{i}\left[E_{c}\right]_{i}\left[\psi_{c}\right]_{i}+\sum_{i=1}^{N_{t}-1} H_{i}[S]_{i}\left[\psi_{m}\right]_{i}
$$




$$
\begin{aligned}
& {\left[C_{D}\right]=\sum_{i=1}^{N_{l}} \frac{1}{2}\left(z_{t}^{2}-z_{b}^{2}\right)_{i}\left[E_{c}\right]_{i}\left[\psi_{c}\right]_{i}+\sum_{i=1}^{N_{l}-1} z_{\tau p, i} H_{i}[S]_{i}\left[\psi_{m}\right]_{i}} \\
& {\left[D_{D}\right]=\sum_{i=1}^{N_{l}} \frac{1}{3}\left(z_{t}^{3}-z_{b}^{3}\right)_{i}\left[E_{c}\right]_{i}\left[\psi_{c}\right]_{i}+\sum_{i=1}^{N_{l}-1} z_{r p, i}^{2} H_{i}[S]_{i}\left[\psi_{m}\right]_{i}}
\end{aligned}
$$

The interply distortion energy coefficient $H$, and matrix $[\mathrm{S}]$ are described in ref. 2. $\left[E_{c}\right]$ is the ply stiffness matrix described in Appendix by equations (A13-A15), and $\left[\psi_{m}\right]$ is the matrix damping in an analogous formulation to equation (5).

The advantages of such representation vs. a single value for the total laminate damping are apparent, as the damping matrix formulation identifies the contribution which a particular deformation mode, such as extension, bending, torsion, coupling between torsion and bending, and coupling between extension and flexure, will have on the total damping of the laminate. The theory is applicable to any laminate configuration. The analogous formulation to the laminate stiffness will facilitate the calculation of structural modal damping via finite element analysis. The dissipated strain energy per unit area per cycle $\delta W$ is directly related to the 3 previous damping matrices, and the midsurface deformation $\left\{\epsilon^{\mathbf{0}}, \kappa\right\}$,

$$
\delta W=\frac{1}{2}\left\{\epsilon^{\circ} \quad \kappa\right\}\left[\begin{array}{ll}
{\left[A_{D}\right]} & {\left[C_{D}\right]} \\
{\left[C_{D}\right]} & {\left[D_{D}\right]}
\end{array}\right]\left\{\begin{array}{c}
\epsilon^{\circ} \\
\kappa
\end{array}\right\}
$$

The stored strain energy per unit area per cycle is

$$
W=\frac{1}{2}\left\{\begin{array}{ll}
\epsilon^{\mathbf{o}} & \kappa
\end{array}\left[\begin{array}{ll}
{[A]} & {[C]} \\
{[C]} & {[D]}
\end{array}\right]\left\{\begin{array}{l}
\epsilon^{\mathbf{o}} \\
\kappa
\end{array}\right\}\right.
$$

The laminate SDC is,

$$
\psi=\frac{\delta W}{W}
$$

Equations (7-12) indicate that the damping capacity of the laminate depends on: (1) the material properties, (2) the laminate configuration, (3) the hygro-thermal parameters, and (4) the deformed shape of the laminate. 
Figures 4, 5, and 6 present the SDC of various laminates at various rotations about the structural $z$-axis (vertical to the laminate plane) described by the outer ply angle $\theta$ with respect to the structural $\mathrm{x}$-axis. Each laminate is subjected to a cyclic in-plane bending moment (free flexure) applied always vertically to the xz-plane. Predicted SDC values with and without the interply matrix effect are compared to experimental data of ref. 14 . It is assumed that no excess of matrix exists between the plies, hence the thickness of the interply layer is:

$$
\delta L=\left(\sqrt{\frac{\pi}{k_{f}}}-2\right) \frac{d_{f}}{2}
$$

The composite plies in all 3 laminates were 0.01 in $(0.254 \mathrm{~mm})$ thick, 50\% FVR HMS/DX209 epoxy. The mechanical properties of this composite system are shown in Table 1. The elastic properties of the epoxy matrix were simulated with the Lewis IMHS epoxy. Fiber and matrix SDC's were back- calculated from on-axis ply values reported in ref. 14 .

Figure 4 represents the flexural SDC of a regular antisymmetric $(\theta /-\theta / \theta \ldots)$ laminate consisting of 10 plies. Both predictions are in good agreement, and the inclusion of interply damping has enhanced the damping prediction.

Figure 5 shows the flexural SDC of an 8-ply $(\theta / 90+\theta / 45+\theta /-45+\theta)_{S}$ laminate with and without interlaminar damping. Again, both curves follow the trend of the experimental measurements. However, the curve without the interlaminar damping effect significantly underestimates the measured damping values, while the incorporation of interply damping has significantly improved the accuracy. The experimental SDC value at 112 degrees cannot be explained. Further insight regarding the damping performance of composite laminates may be obtained from Figure 5 . The laminate will reach its maximum flexural stiffness at the $(0 / 90 / 45 /-45)_{S}$ and $(90 / 0 /-45 / 45)_{S}$ configurations which correspond to the points of lower flexural damping in Figure 5. On the other hand, configurations with low flexural (but high torsional) stiffness, such as $(45 /-45 / 90 / 0)_{S}(\theta=45$ degrees) and $(-45 / 45 / 0 / 90)_{s}(\theta=135$ degrees $)$ will provide high flexural damping. The results for the $(\theta /-60+\theta / 60+\theta)_{S} 6$-ply laminate in Figure 6 also validate the accuracy and reliability of the method. The incorporation of interlaminar damping has again improved the damping 
prediction.

The damping predictions in Figures 4-6 underestimate the experimental values. This is natural, because the experimental measurements may include damping from sources other than the specimen. Temperature rise and moisture in the specimen may also increase the laminate damping, as is explained in the following paragraphs. $\mathrm{Ni}$ and Adams in a latter paper ${ }^{20}$ acknowledged existence of extraneous damping in the previous experimental data and reported new experimental measurements for the basic $(\theta / 90+\theta / 45+\theta /-45+\theta)_{S}$ laminate of $50 \%$ FVR HM-S/DX210 graphite/epoxy. The experimental data, together with predicted values of the present theory, are plotted in Figure 7. The mechanical properties of the composite are shown in Table 1. Interestingly, the underestimation of the predicted results is reduced, and the results with the interlaminar damping are in excellent agreement with the measured data. Figure 7 also shows predicted damping values by $\mathrm{Ni}$ and Adams as reported in ref. 20. The accuracy and superiority of the present damping theory is self-explanatory.

To the authors' best knowledge, the SDC prediction without interlaminar effects seems to be the upper bound of accuracy of other reported theories. All examples illustrate tremendous potential for tailoring the damping and stiffness of composite off- axis laminates with respect to their projected mission. It worths to point out that although the last two basic laminate configurations are quasisotropic and their in-plane stiffnesses do not vary with $\theta$, their out-of-plane flexural SDC's exhibit wide variations with respect to the rotation angle $\theta$.

Hygro-Thermal Effect. As stated previously, variations of temperature and moisture may have significant effect on the elastic and damping properties of composite plies, consequently, hygro-thermal variations will influence the damping performance of composite laminates. The hygro-thermal effect on composite laminates can be modeled through equations (1-4), (7), (8), and (9). Figure 8 presents the flexural SDC of the previously described $(\theta / 90+\theta / 45+\theta /-45+\theta)_{S}$ HM- S/DX209 laminate at : (1) reference temperature and $0 \%$ moisture, $(2) 200^{\circ} \mathrm{F}\left(111^{\circ} \mathrm{C}\right)$ above reference temperature and $0 \%$ moisture, and 
(3) $200^{\circ} \mathrm{F}\left(111^{\circ} \mathrm{C}\right)$ above reference temperature and $2 \%$ moisture. Clearly, the hygrothermal effect on laminate damping may be significant, particularly at laminate orientations where the applied load is mainly carried by transverse and shear ply stresses.

\section{Thermo-Mechanical Laminate Response}

The dissipated strain energy is transferred from the laminate to the environment. As a result, temperature distributions will be developed within the vibrating laminate which will alter most mechanical properties including damping. The developed temperature profiles will also affect the moisture content in the laminate. Gradually, the vibrating laminate will reach a steady-state response of thermal equilibrium, which may be identified as steady-state hygro-thermo-mechanical response. The steady-state heat-transfer problem is solved based on Fourier's heat transfer law. The steady-state temperature distribution is iteratively calculated based on the secant numerical scheme, such that the thermo-mechanical properties of the laminate are updated at each iteration. This recursive procedure is rapidly converging. An application example is illustrated in Table 2 , for an off- axis $(40)_{4}$ thick ply subjected to cyclic stressing in $\mathrm{x}$-direction of $10 \mathrm{kpsi}(69 \mathrm{MPa}$ ) amplitude at $50 \mathrm{~Hz}$. The laminate is composed of four 50\% FVR HM-S/IMHS graphiteepoxy plies, each 0.005 in $(0.127 \mathrm{~mm})$ thick. Table 2 presents the initial temperature, the calculated temperature for 1 iteration with properties at reference temperature, and the calculated temperature after convergence in 5 iterations. The utilization of the iterative technique has resulted in $8 \%$ higher temperature and $7 \%$ higher damping. Due to the nonlinear nature of the hygrothermal composite behavior, the error will be higher for higher excitation loads, higher environment temperatures, and moisture in the material. In this case the recursive procedure should be applied.

The concept of temperature rise in off-axis laminates is further illustrated for the case of the basic $(\theta / 90+\theta / 45+\theta /-45+\theta)_{S} 8$-ply laminate described in the previous sections. Table 3 shows the resultant temperature profiles across the laminate when a sinusoidal bending moment of $20 \mathrm{lb}$-in $(2.26 \mathrm{~N}-\mathrm{m})$ at $50 \mathrm{~Hz}$ is applied vertically to the xz-plane. One iteration was used in the calculations, the air conductivity was assumed equal to that 
of motionless air, and interlaminar damping was included. Four different orientations of the laminate are studied in Table 3. As seen in Figures 5 or 8 , the $(0 / 90 / 45 /-45)_{S}$ and $(90 / 0 /-45 / 45)_{S}$ configurations are the ones with lower flexural SDC and exhibit low temperature rise, while the $(45 /-45 / 90 / 0)_{S}$ and $(-45 / 45 / 0 / 90)_{S}$ are the ones with high flexural SDC values and exhibit much higher temperature profiles. The temperature rises are disproportional to the damping variation, therefore, gains in laminate damping may be penalized by undesirable high temperature. Most of the temperature increase has resulted due to the thermal resistance of the surrounding air, hence, the temperature rise will drastically depend on the actual boundary conditions of each individual thermal problem. In view of the assumed air conductivity, the results in Table 3 represent upper bounds for the temperature increase.

\section{Summary}

Damping mechanics have been developed for modelling the coupled mechanical, thermal, and hygral response of composite laminates. The mechanics theory is used to predict damping properties of composite plies and laminates and the interaction with parameters such as temperature and moisture. A new micromechanics theory for the prediction of damping in composite plies has been also integrated into the method. The methodology is applicable to any laminate type, as it includes damping induced by extension, flexure, and extension-flexure coupling.

The overall accuracy of the method has been demonstrated through various case studjes and correlations with available experimental measurements. The main conclusions of the study are summarized in the rest of the paragraph. With the exception of longitudinal normal damping, the on-axis ply damping has been shown to be mainly matrix controlled. The effect of temperature and moisture appears significant to matrix controlled SDC's such as transverse normal, in-plane shear, and out-off-plane shear SDC. The fiber controlled longitudinal SDC seems insensitive to hygro-thermal parameters. Off-axis damping significantly varies with the ply angle indicating wide margins for damping tailoring. Incorporation of interlaminar damping in the formation of laminate damping was proved to 
be a critical missing factor to the modeling accuracy of the method. The laminate damping depends on laminate configurations, ply orientations, and local deformation. Any variation of these parameters would dramatically change the laminate damping capacity. In this context, the damping of composite laminates has a greater potential for tailoring, in conjunction to other laminate properties, as a result of ply interactions and direct dependence to local deformation. The laminate damping was also found sensitive to variations of temperature and moisture. Finally, the thermo-mechanical steady-state response of vibrating composite laminates has been investigated. Predictions of the resultant temperature profiles in vibrating composite laminates indicate that laminates with high damping capacity subjected to continuous vibration may exhibit high temperature rises.

The present theory has been integrated into the ICAN (Integrated Composites Analyzer) computer code. In this manner, the computational capabilities for composite analysis have been expanded to include the analysis of composite damping and, thus, making ICAN a useful computer-aided-design tool in tailoring the damping of composite laminates. Furthermore, it provides the background for subsequent formal simulation and optimization of the coupled hygro-thermo-mechanical response of composite structures.

\section{Acknowledgement}

This work was performed while the author held a National Research Council - NASA Research Associateship. 


\section{References}

1. Daniel, I. M. and Liber, T., "Lamination Residual Stresses in Fiber Composites Interim Report," NASA CR-134826, March 1975.

2. Murthy, P. L. N. and Chamis, C. C., "ICAN: Integrated Composite Analyzer," AIAA Paper 84-0974, May 1984.

3. Hashin Z., "Complex Moduli of Viscoelastic Composites - II. Fiber Reinforced Composite Materials," International Journal of Solids and Structures, Vol. 6, 1970, pp. $797-807$.

4. Adams, R. D., Fox, M. A. O., Flood, R. J. L., Friend, R. J. and Hewitt, R. L., "The Dynamic Properties of Unidirectional Carbon and Glass Fiber-Reinforced Plastics in Torsion and Flexure," Journal of Composite Materials, Vol. 3, 1969, pp. 594-603.

5. Ni, R. G. and Adams, R. D., "A Rational Method for Obtaining the Dynamic Mechanical Properties of Laminae for Predicting the Stiffness and Damping of Laminated Plates and Beams," Composites, Vol. 15, No. 3, July 1984, pp. 193-199.

6. Chang, S. and Bert, C. W., "Analysis of Damping for Filamentary Composite Materials," Composite Materials in Engineering Design, American Society for Metals, Metals Park, 1973, pp. 51-62.

7. Gibson, R. F. and Plunkett, R., "Dynamic Mechanical Behavior of Fiber-Reinforced Composites: Measurement and Analysis," Journal of Composite Materials, Vol. 10, Oct. 1976 , pp. 325-341.

8. Sun, C. T., Chaturvedi, S. K. and Gibson, R. F., "Internal Damping of Short-Fiber Reinforced Polymer Matrix Composites," Computers and Structures, Vol. 20, No. 1-3, 1985, pp. 391-400.

9. Suarez, S. A., Gibson, R. F., Sun, C. T. and Chaturvedi, S. K., "The Influence of Fiber Length and Fiber Orientation on Damping and Stiffness of Polymer Composite Materials," Experimental Mechanics, Vol. 26, No. 2, 1986, pp. 175-184.

10. Mantena, R., Gibson, R. F. and Place, T. A., "Damping Capacity Measurements of Degradation in Advanced Materials," SAMPE Quarterly, Vol. 17, No. 3, April 1986, 
pp.. 20-31.

11. Schultz, A. B. and Tsai, S. W., "Dynamic Moduli and Damping Ratios of Fiber Reinforced Composites," Journal of Composite Materials, Vol. 2, No.3, Jul. 1968, pp. 368-379.

12. Schultz, A. B. and Tsai, S. W., "Measurements of Complex Dynamic Moduli for Laminated Fiber-Reinforced Composites," Journal of Composite Materials, Vol. 3, 1969, pp. 434-443.

13. Adams, R. D. and Bacon, D. G. C., "Effect of Fibre Orientation and Laminate Geometry on the Dynamic Properties of CFRP," Journal of Composite Materials, Vol. 7, Oct. 1973, pp. 402-428.

14. Bacon, D. G. C., "The Dynamic Properties of Carbon and Glass Fibre Reinforced Plastics," Ph.D Dissertation, Bristol University, UK, 1973.

15. Siu, C. C. and Bert, C. W., "Sinusoidal Response of Composite-Material Plates with Material Damping," ASME Journal of Engineering for Industry, May 1974, pp. 603610.

16. Saravanos, D. A. and Chamis, C. C., "Unified Micromechanics of Damping for Unidirectional Fiber Composites," NASA TM-102107, 1989.

17. Chamis, C. C., "Simplified Composite Micromechanics Equations for Hygral, Thermal, and Mechanical Properties," SAMPE Quarterly, Vol. 15, No. 3, April 1984, pp. 14-23.

18. Caruso, J. J. and Chamis, C. C., "Assessment of Simplified Composite Micromechanics Using Three-Dimensional Finite-Element Analysis," Journal of Composites Technology and Research, Vol. 8, No. 3, 1986, pp. 77-83.

19. Chamis, C. C., Lark R. F. and Sinclair, J. H., "Integrated Theory for Predicting the Hygrothermomechanical Response of Advanced Composite Structural Components," Advanced Composite Materials - Environmental Effects, ASTM STP-658, American Society for Testing and Materials, 1978, pp. 160-192.

20. Ni, R. G. and Adams, R. D., "The Damping and Dynamic Moduli of Symmetric Laminated Composite Beams - Theoretical and Experimental Results," Journal of 
Composite Materials, Vol. 18, March 1984, pp. 104-121. 


\section{Appendix}

Longitudinal normal ply $\operatorname{SDC} \psi_{l 11}$ :

$$
\psi_{l 11}=\psi_{f 11} k_{f} \frac{E_{f 11}}{E_{l 11}}+\psi_{m n} k_{f} \frac{E_{m}}{E_{l 11}}
$$

Transverse normal ply SDC's $\psi_{l 22}, \psi_{l 33}$ :

$$
\begin{gathered}
\psi_{l 22}=\psi_{f 22} \sqrt{k_{f}} \frac{E_{22}}{E_{f 22}}+\psi_{m n}\left(1-\sqrt{k_{f}}\right) \frac{E_{22}}{E_{m}} \\
\psi_{l 33}=\psi_{l 22}
\end{gathered}
$$

where,

$$
E_{22}=\left(1-\sqrt{k_{f}}\right) E_{m}+\frac{\sqrt{k_{f}} E_{m}}{1-\sqrt{k_{f}}\left(1-\frac{E_{m}}{E_{f 22}}\right)}
$$

In-plane shear ply SDC $\psi_{l 12}$ :

$$
\psi_{l 12}=\psi_{f 12} \sqrt{k_{f}} \frac{G_{12}}{G_{f 12}}+\psi_{m s}\left(1-\sqrt{k_{f}}\right) \frac{G_{12}}{G_{m}}
$$

where,

$$
G_{12}=\left(1-\sqrt{k_{f}}\right) G_{m}+\frac{\sqrt{k_{f}} G_{m}}{1-\sqrt{k_{f}}\left(1-\frac{G_{m}}{G_{f 12}}\right)}
$$

Out-of-plane shear ply SDC's $\psi_{l 23}, \psi_{l 13}$ :

$$
\begin{gathered}
\psi_{l 23}=\psi_{f 23} \sqrt{k_{f}} \frac{G_{l 23}}{G_{f 23}}+\psi_{m s}\left(1-\sqrt{k_{f}}\right) \frac{G_{l 23}}{G_{m}} \\
\psi_{l 13}=\psi_{l 12}
\end{gathered}
$$

where,

$$
\begin{gathered}
G_{l 23}=\frac{E_{l 22}}{2\left(1+\nu_{l 23}\right)} \\
E_{l 22}=\frac{E_{m}}{1-\sqrt{k_{f}}\left(1-\frac{E_{m}}{E_{f 22}}\right)} \\
\nu_{l 23}=\frac{\nu_{m}}{1-k_{f} \nu_{m}}+k_{f}\left(\nu_{f 23}-\frac{\left(1-k_{f}\right) \nu_{m}}{1-k_{f} \nu_{m}}\right)
\end{gathered}
$$




$$
\left[R_{\sigma}\right]=\left[\begin{array}{ccc}
\cos ^{2} \theta & \sin ^{2} \theta & \sin 2 \theta \\
\sin ^{2} \theta & \cos ^{2} \theta & -\sin 2 \theta \\
-0.5 \sin 2 \theta & 0.5 \sin 2 \theta & \cos 2 \theta
\end{array}\right]
$$

On-axis ply stiffness:

$$
\left[E_{l}\right]^{-1}=\left[\begin{array}{ccc}
\frac{1}{E_{l 12}} & -\frac{\nu_{l 21}}{E_{122}} & 0 \\
-\frac{\nu_{122}}{E_{l 12}} & \frac{1}{E_{122}} & 0 \\
0 & 0 & \frac{1}{G_{112}}
\end{array}\right]
$$

Off-axis ply stiffness:

$$
\begin{gathered}
{\left[E_{\mathrm{c}}\right]^{-1}=\left[R_{\sigma}\right]^{T}\left[E_{l}\right]^{-1}\left[R_{\sigma}\right]} \\
{\left[E_{\mathrm{c}}\right]^{-1}=\left[\begin{array}{ccc}
\frac{1}{E_{c x x}} & -\frac{\nu_{c y x}}{E_{c y y}} & \frac{\nu_{c y x}}{G_{c x y}} \\
-\frac{\nu_{c x y}}{E_{c x z}} & \frac{1}{E_{c y y}} & \frac{\nu_{c u y}}{G_{c y y}} \\
\frac{\nu_{c x}}{E_{c x x}} & \frac{\nu_{c y}}{E_{c y y}} & \frac{1}{G_{c x y}}
\end{array}\right]}
\end{gathered}
$$


Table 1. Mechanical properties of HM-S/epoxy systems.

\begin{tabular}{|c|c|c|c|}
\hline $\begin{array}{l}\text { DX209 and DX210 } \\
\text { Epoxies }\end{array}$ & HM-S Graphite & $\begin{array}{l}50 \% \text { HM-S/DX209 } \\
\text { (ref. 14) }\end{array}$ & $\begin{array}{l}\text { 50\% HM-S/DX210 } \\
\text { (ref. 20) }\end{array}$ \\
\hline $\begin{aligned} E_{m} & =0.500 \mathrm{Mpsi} \\
& (3.45 \mathrm{GPa}) \\
G_{m} & =0.185 \mathrm{Mpsi} \\
& (1.27 \mathrm{GPa})\end{aligned}$ & $\begin{aligned} & E_{f 11}=55.0 \mathrm{Mpsi}(379.3 \mathrm{GPa}) \\
& E_{f 22}=0.9 \mathrm{Mpsi} \\
&(6.2 \mathrm{GPa}) \\
& G_{f 12}=1.1 \mathrm{Mpsi} \\
&(7.6 \mathrm{GPa}) \\
& \nu_{f 12}=0.20\end{aligned}$ & $\begin{array}{l}\psi_{l 11}=0.64 \% \\
\psi_{l 22}=6.90 \% \\
\psi_{l 12}=10.00 \%\end{array}$ & $\begin{array}{l}\psi_{l 11}=0.45 \% \\
\psi_{l 22}=4.22 \% \\
\psi_{l 12}=7.05 \%\end{array}$ \\
\hline
\end{tabular}


Table 2 Initial and calculated temperature distribution in a vibrating $(40)_{4}$ thick ply.

\begin{tabular}{|c|c|c|c|}
\hline Quantity & Initial & 1 iteration & $\begin{array}{l}5 \text { iterations } \\
\text { (converged) }\end{array}$ \\
\hline Ply SDC, \% & - & 3.73 & 4.01 \\
\hline 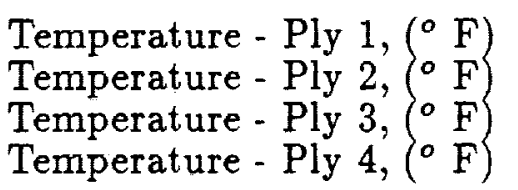 & $\begin{array}{l}70.00 \\
70.00 \\
70.00 \\
70.00\end{array}$ & $\begin{array}{l}110.27 \\
110.48 \\
110.48 \\
110.27\end{array}$ & $\begin{array}{l}120.23 \\
120.54 \\
120.54 \\
120.23\end{array}$ \\
\hline
\end{tabular}

Table 3 Predicted temperature distributions in vibrating laminates. Temperatures are above the reference temperature $\left(70^{\circ} \mathrm{F}\right)$.

\begin{tabular}{ccccc}
\hline \hline & $\begin{array}{c}\text { Temperature, }\left({ }^{\circ} \mathrm{F}\right) \\
\text { Ply }\end{array}$ & $\begin{array}{c}\text { Temperature, }\left({ }^{\circ} \mathrm{F}\right) \\
(90 / 0 / 45 /-45)_{s}\end{array}$ & $\begin{array}{c}\text { Temperature, }\left({ }^{\circ} \mathrm{F}\right) \\
(45 /-45 / 45 / 0)_{s}\end{array}$ & $\begin{array}{c}\text { Temperature, }\left({ }^{\circ} \mathrm{F}\right) \\
(-45 / 45 / 0 / 90)_{s}\end{array}$ \\
\hline 1 & 2.92 & 7.37 & 72.11 & 48.23 \\
2 & 2.97 & 7.49 & 73.23 & 48.98 \\
3 & 3.00 & 7.57 & 73.98 & 49.48 \\
4 & 3.01 & 7.61 & 74.35 & 49.73 \\
5 & 3.01 & 7.61 & 74.35 & 49.73 \\
6 & 3.00 & 7.57 & 73.98 & 49.48 \\
7 & 2.97 & 7.49 & 73.23 & 48.98 \\
8 & 2.92 & 7.37 & 72.11 & 48.23 \\
\hline \hline
\end{tabular}




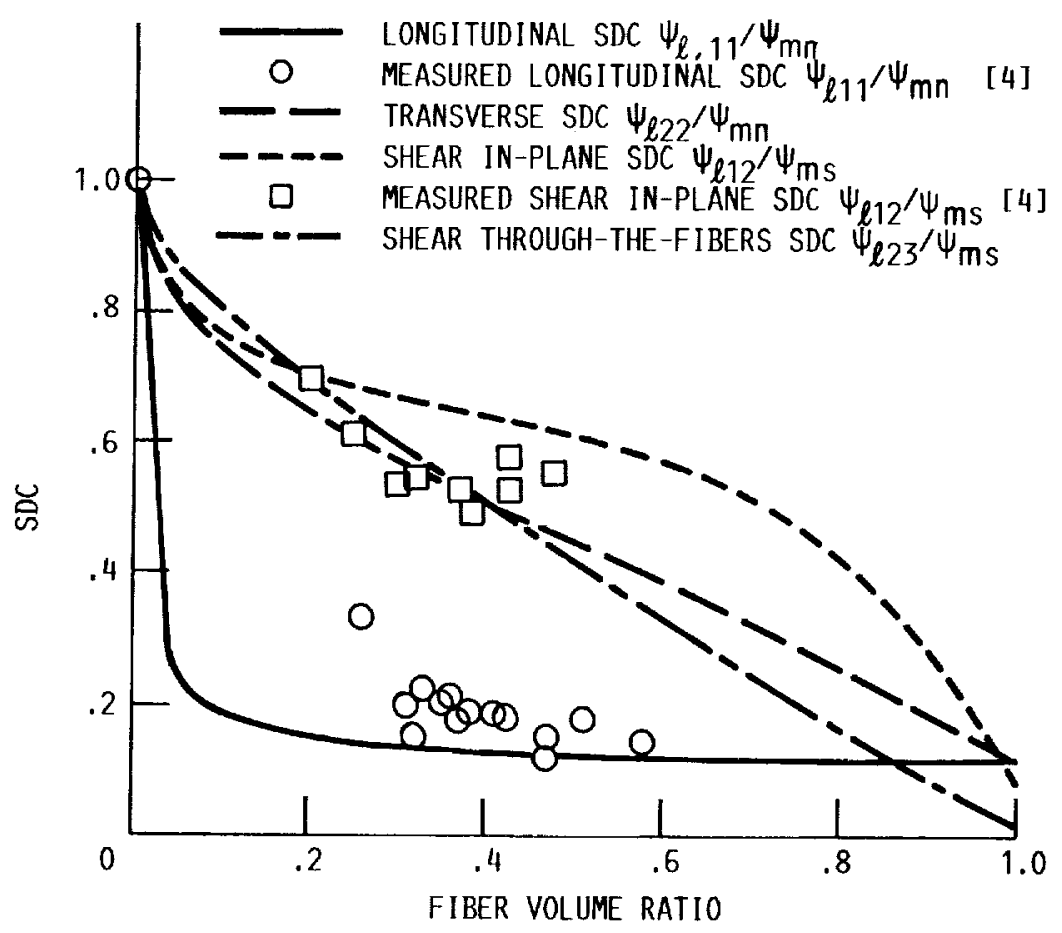

FIGURE 1. - TYPICAL ON-AXIS SDC'S FOR A HM-S (HIGH MODULUS SURFACE TREATED GRAPHITE)/POLYESTER SYSTEM. NORMAL AND SHEAR SDC'S ARE RESPECTIVELY NORMALIZED BY THE NORMAL AND SHEAR SDC OF THE MATRIX.

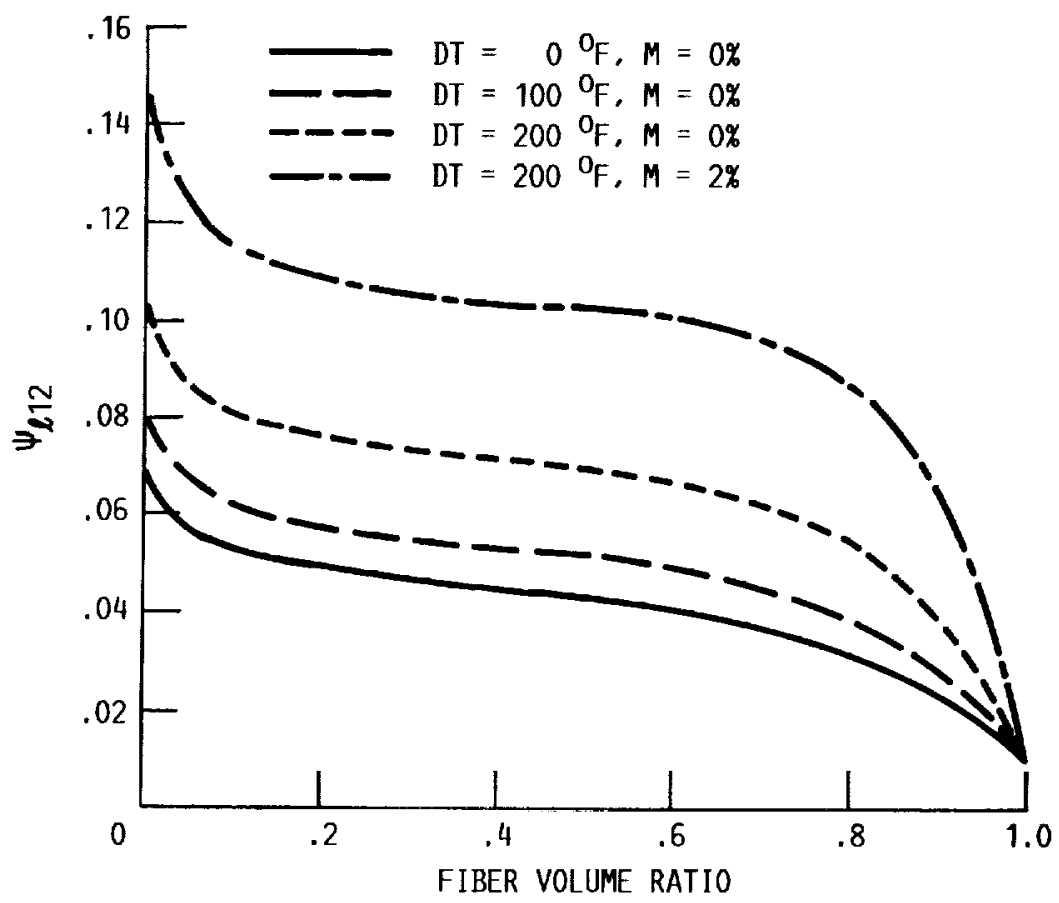

FIGURE 2. - HYGROTHERMAL EFFECT ON IN-PLANE SHEAR SDC FOR A HM-S/EPOXY SYSTEM. 


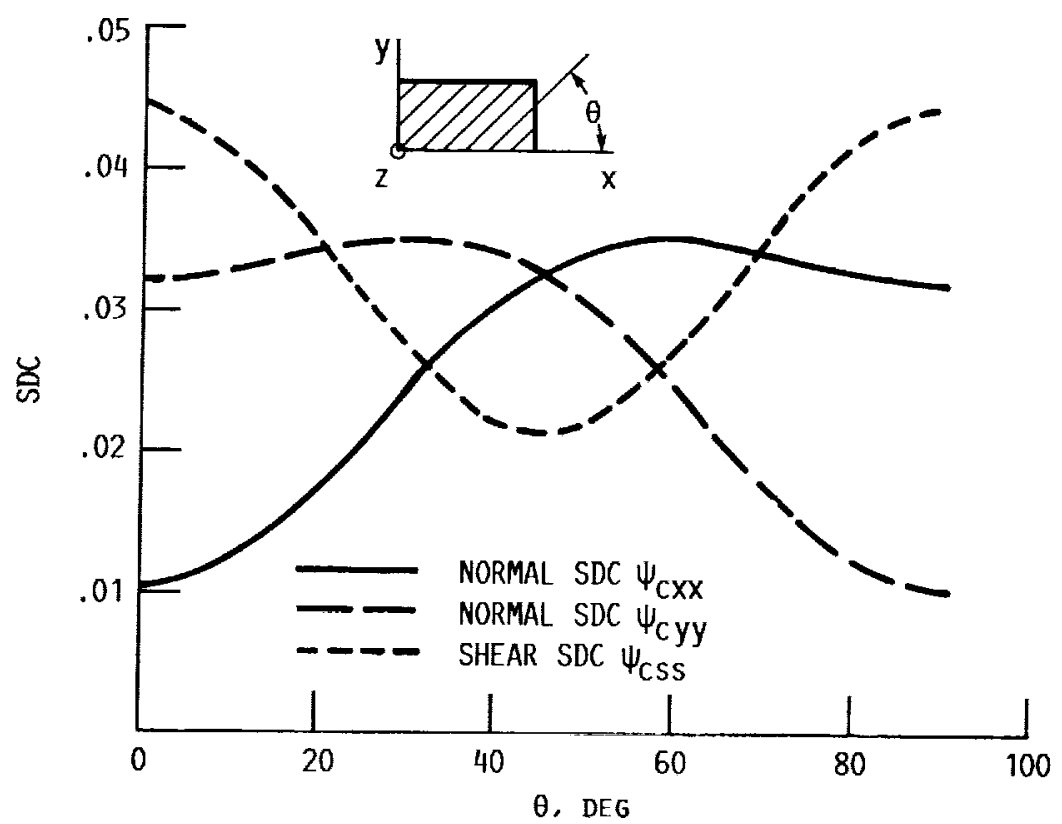

FIGURE 3. - OFF-AXIS IN-PLANE SDC'S FOR A 50 PERCENT

HM-S/EPOXY UNIDIRECTIONAL PLY VERSUS THE PLY ANGLE.

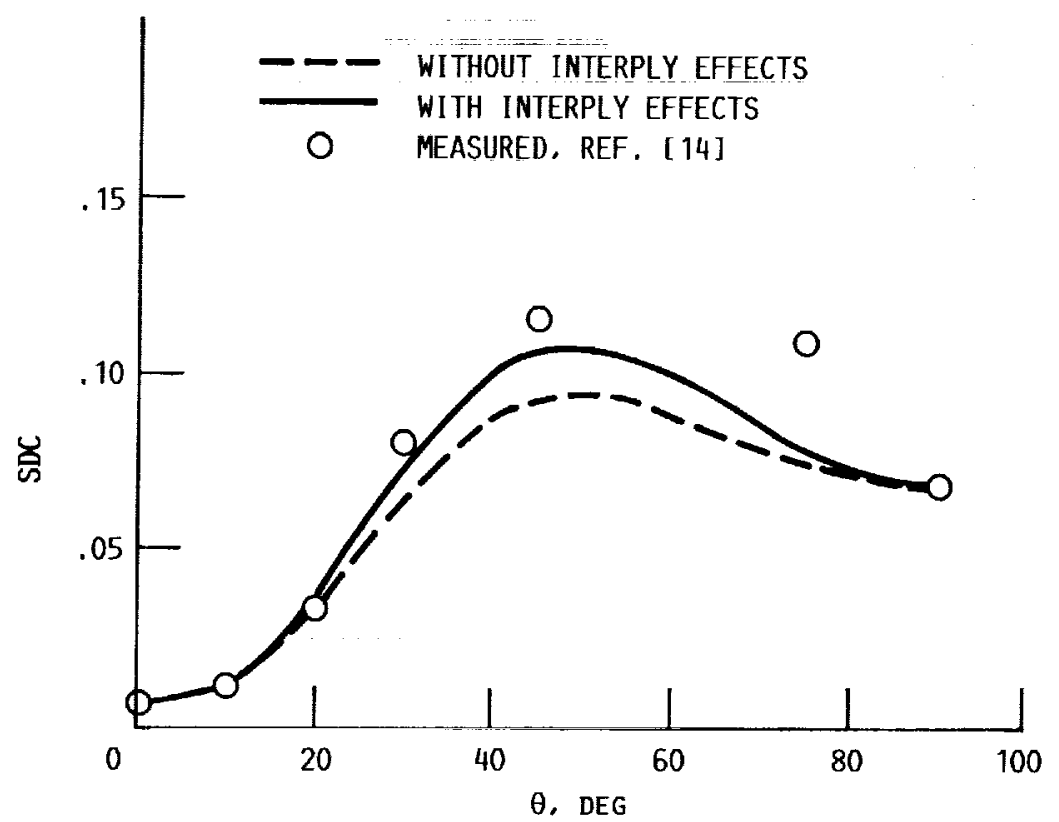

FIGURE 4. - FLEXURAL SDC OF A 50 PERCENT HM-S/DX209 $(\theta /-\theta / \theta \ldots)$ REGULAR LAMINATE, 


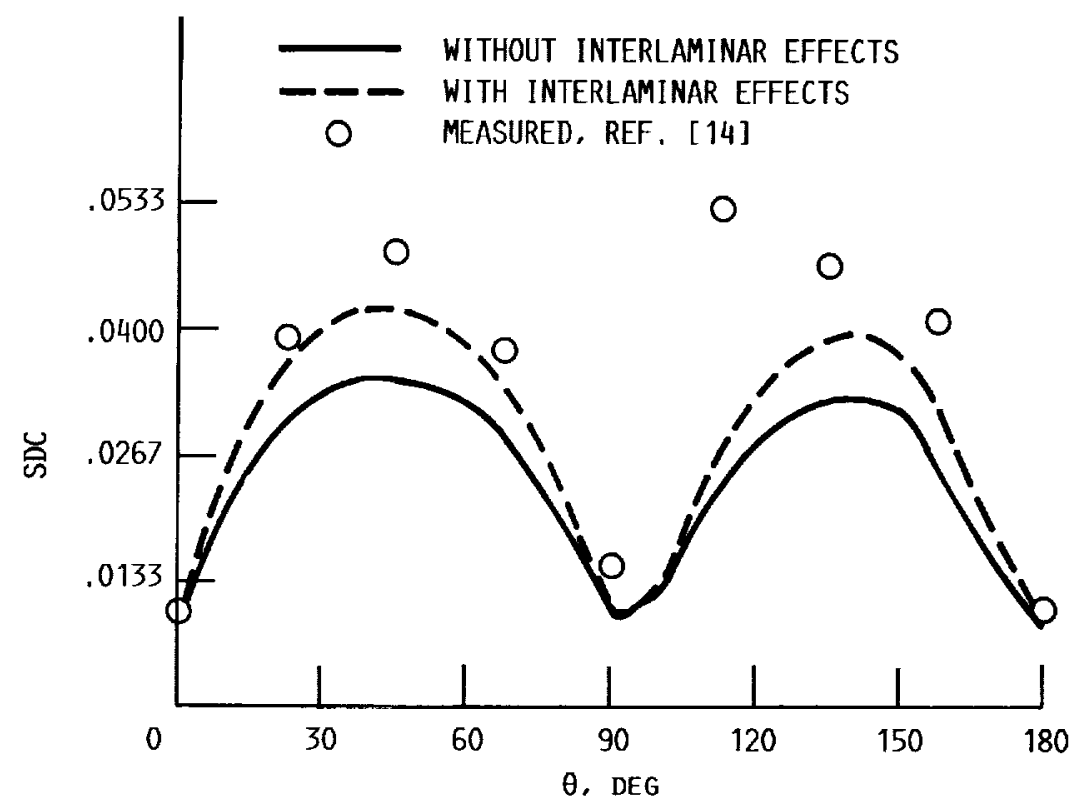

FIGURE 5. - FLEXURAL SOC OF A 50 PERCENT FVR HM-S/DX209 $(\theta / 90+\theta / 45+\theta /-45+\theta)$ s LAMINATE.

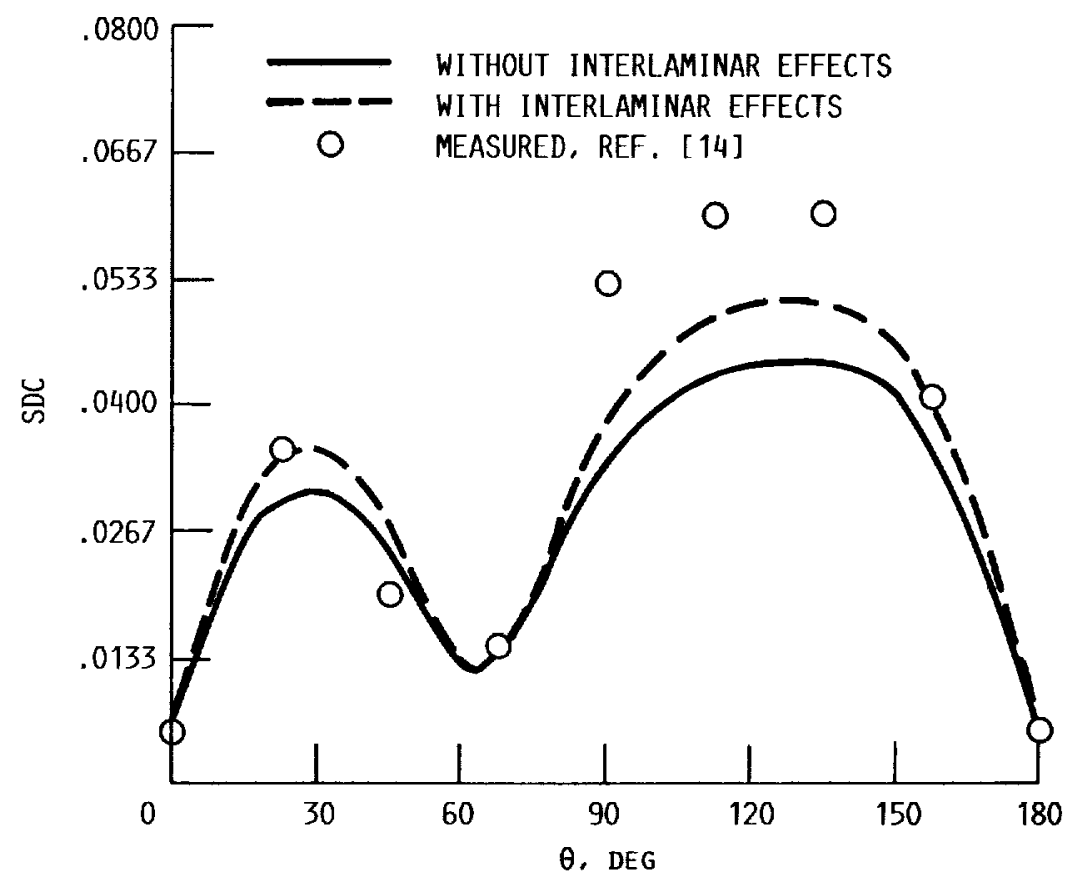

FIGURE 6. - FLEXURAL SDC OF A 50 PERCENT FVR HM-S/ DX209 $(\theta /-60+\theta / 60+\theta)_{S}$ LAMINATE. 


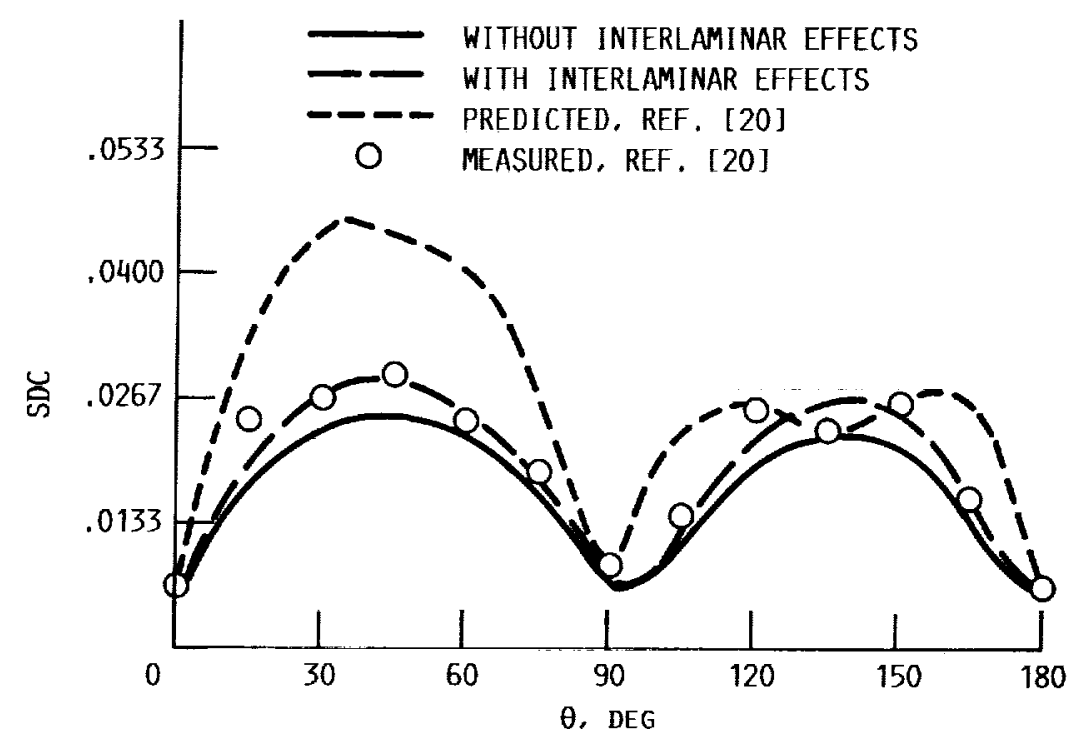

FIGURE 7. - FLEXURAL SDC OF A 50 PERCENT FVR HM-S/DX210 $(\theta / 90+\theta / 45+\theta /-45+\theta)_{s}$ LAMINATE.

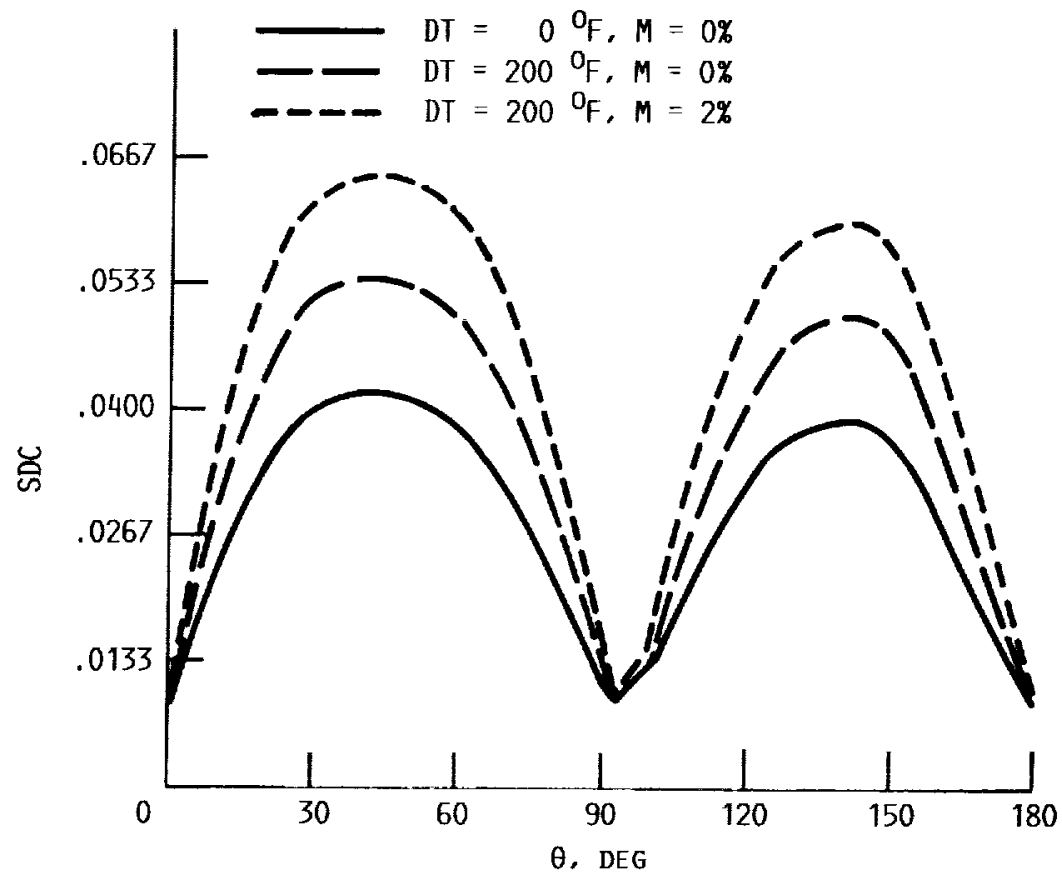

FIGURE 8. - HYGROTHERMAL EFFECT ON THE FLEXURAL SDC OF A 50 PERCENT FVR HM-S/DX209 $(\theta / 90+\theta / 45+\theta /-45+\theta)_{S}$ LAMINATE. 


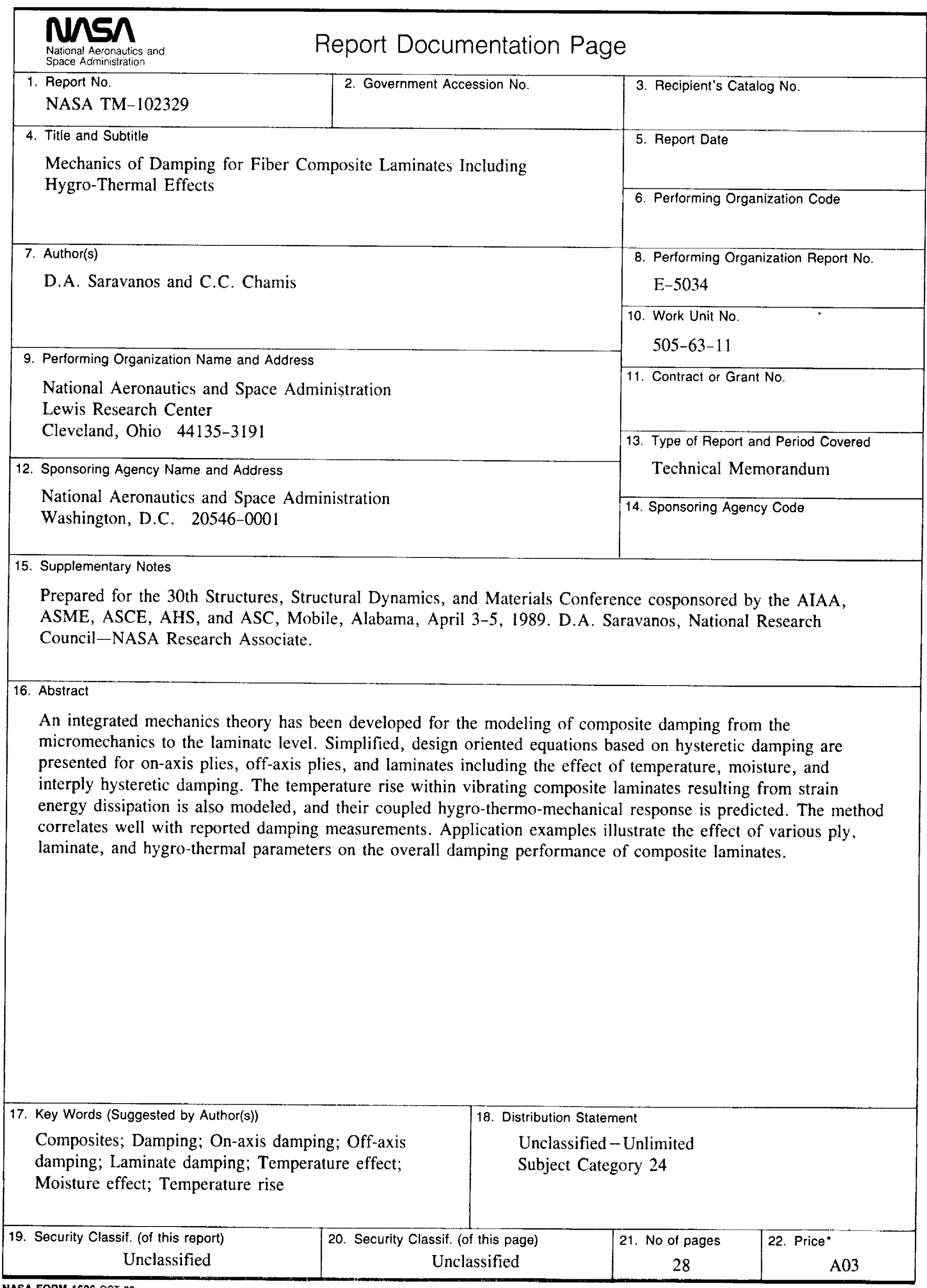


